\title{
Regulation of Bile Salt Pool Size in Man
}

\author{
THOMAS S. LOW-BEER, ERU W. POMARE
}

\section{Summary}

When the enterohepatic circulation is intact the size of the bile salt pool is largely determined by the frequency of its enterohepatic circulation. This hypothesis, derived from studies of cholate kinetics in coeliac, cholecystectomy, and gall stone patients, represents the simplest interpretation of the data. A corollary is that daily cholate secretion is likely to be normal in these conditions and that therefore the propensity of bile to form cholesterol gall stones is not likely to be directly related to bile salt pool size.

\section{Introduction}

Bile salts are synthesized by the liver from cholesterol (Bergström and Danielsson, 1968; Mosbach, 1972). They are secreted into the biliary tract and stored between meals in the gall bladder. When food enters the duodenum, bile is discharged into the intestine under the influence of cholecystokinin and the enterohepatic circulation is set in motion. Over $90 \%$ of the bile salts are absorbed in the terminal ileum and returned to the liver via the portal venous system. Of those bile salts passing into the colon about $3-5 \%$ are excreted and the rest reabsorbed (Heaton, 1972; Hepner et al., 1972). On reaching the liver bile salts are efficiently extracted from the portal blood and resecreted into the bile. Such an enterohepatic circulation occurs two or more times with each major meal. Since the pool of bile salt in the enterohepatic circulation normally remains in a steady state, new hepatic systhesis must replace what is lost in the faeces. The evidence for bile salt feedback regulation of this synthesis is strong (Low-Beer et al., 1972; Mosbach, 1972; Small et al., 1972). It is the purpose here to try to determine the factors most likely to be important in regulating pool size in the context of a homeostatically controlled system. It has been tentatively suggested (Vlahcevic et al., 1970, 1972; Danzinger et al., 1972; Grundy et al., 1972; Schaffer et al., 1972) that the small bile salt pool in patients with cholesterol gall stones (Vlahcevic et al., 1970, 1972; Bell et al., 1972) might account for the relative excess of cholesterol over bile salt and phospholipid in the bile they secrete (Admirand and Small, 1968). The regulation of bile salt pool size might thus assume clinical importance in the aetiology of gall stones.

\section{Methods}

The kinetics of the enterohepatic circulation of bile salts have been studied at Bristol by labelling the bile salt pool with a known tracer dose of a radioactive bile salt, taurocholate, and measuring the rate of fall on its specific radioactivity in bile aspirated from the duodenum on consecutive days. From this

\footnotetext{
University Department of Medicine, Bristol Royal Infirmary, Bristol BS2 8HW

THOMAS S. LOW-BEER, M.R.C.P., Lecturer in Medicine ERU W. POMARE, M.R.A.C.P., Research Fellow
}

one can calculate the pool size and half life of taurocholate.in the enterohepatic circulation and derive daily synthesis (= excretion) from the formula (Austad et al., 1967):

Daily synthesis $=$ Pool size $\times 0.693$

$$
\text { half life }
$$

The half life is an index of the rate of excretion of taurocholate from its pool. Assuming that each time the pool circulates a certain percentage of the pool is excreted, then the half life depends on the frequency of circulation of the pool, on its rate of metabolism, and on the efficiency of ileal reabsorption (Hofmann et al., 1970).

Patients with coeliac disease (Low-Beer et al., 1971, 1973), cholecystectomy patients, and their age- and sex-matched normal controls (Pomare and Heaton, 1973) have been studied in this way.

\section{Results}

\section{COELIAC DISEASE}

In adult coeliac disease the frequency of enterohepatic circulation is reduced, presumably owing to deficient cholecystokinin release from the damaged upper small intestinal mucosa (Low-Beer et al., 1971; Di Magno et al., 1972). Gall bladder contraction after food is impaired (Low-Beer et al., 1971), and entry of bile into the intestine delayed (Di Magno et al., 1972). The half life of taurocholate in the patients studied was doubled (see table) compatible with infrequent cycling of the pool. The taurocholate pool was increased two to threefold, and accounted for a similar proportion of the total bile salt pool in coeliac patients and control subjects. The daily synthesis and excretion of taurocholate remained similar to control subjects. When the pool size of taurocholate is plotted against its half life in the enterohepatic circulation for each patient a significant correlation emerges $(r=0.88, P<0.01)$.

Taurocholate Kinetics in Coeliac and Cholecystectomy Patients and Control Subjects (Mean \pm S.D.)

\begin{tabular}{|c|c|c|c|c|c|}
\hline & No. & $\begin{array}{l}\text { Pool Size } \\
\text { (mg) }\end{array}$ & $\underset{\text { (Days) }}{\text { Half Life }}$ & $\begin{array}{l}\text { Synthesis } \\
\text { (mg) }\end{array}$ & $\begin{array}{c}\text { Taurocholate } \\
\text { Total Bile Salts } \\
\text { as Mean \% }\end{array}$ \\
\hline $\begin{array}{l}\text { Coeliac disease . . } \\
\text { Cholecystectomy } \\
\text { Control subjects. . }\end{array}$ & $\begin{array}{r}9 \\
11 \\
10\end{array}$ & $\begin{array}{r}1,075 \pm 776^{*} \\
210 \pm 117^{*} \\
358 \pm 177\end{array}$ & $\begin{array}{l}3.24 \pm 1.54^{*} \\
0.97 \pm 0.30^{*} \\
1.65 \pm 0.61\end{array}$ & $\begin{array}{l}211 \pm 95 \\
142 \pm 63 \\
149 \pm 47\end{array}$ & $\begin{array}{l}13 \cdot 4 \\
13 \cdot 1 \\
12 \cdot 7\end{array}$ \\
\hline
\end{tabular}

*Signifis ant difference from control subjects.

\section{CHOLECYSTECTOMY}

When the storage site for bile has been removed by cholecystectomy bile is likely to flow into the intestine almost continuously, in contrast to the phasic circulation in normal people (Pomare and Heaton, 1973). Cholecystokinin administered to cholecystectomy patients does not increase bile salt secretion (Malagelada et al., 1972), and in rats, which have no gall bladder, most of the bile salt pool between meals is in the ileum, where bile salts are absorbed (Boyd and Eastwood, 1968).

In cholecystectomy patients taurocholate pool and half life were each reduced by between a third and a half, and were significantly correlated $(r=0.77, P<0.01)$. Neither daily 
synthesis of taurocholate nor its proportion of the total bile salt pool differed significantly from normal.

The regression lines for taurocholate pool $v$. half life in coeliac disease, cholecystectomy patients, and control subjects were not statistically different either as regards distance or slope, and the data from the three groups could be pooled $(r=0.92, P<0.001$ ) (fig. 1). This suggests that the same factors are responsible for maintaining this relation in coeliac and cholecystectomy patients and normal controls.

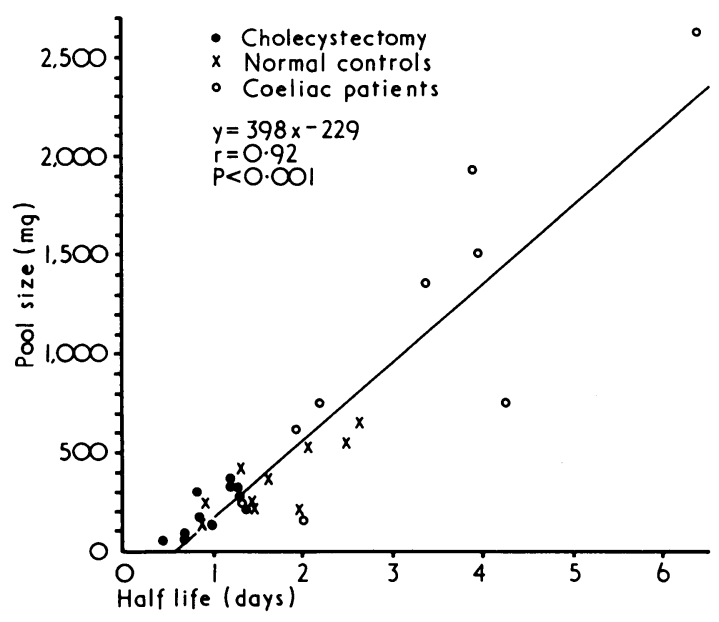

FIG. 1-Taurocholate pool size plotted against its half life in enterohepatic circulation for coeliac and cholecystectomy patients and their controls.

\section{Discussion}

In coeliac and cholecystectomy patients taurocholate synthesis remains normal in spite of significant differences in taurocholate pool size. Since taurocholate constitutes a normal proportion of the bile salt pool in these patients their total bile salt pool is altered to a similar degree. For synthesis to remain normal in the face of changes in pool size both half life and pool size must change in parallel, and this we have shown to occur. If, in this homeostatic system, the half life of taurocholate had been altered as a result of changes in the amount of taurocholate excreted or metabolized, one would have expected either the synthesis or the proportion of taurocholate to the total bile salt pool to be altered. Therefore, it seems that the long half life in coeliac disease is due to a normal daily excretion of taurocholate from an abnormally large pool circulating more sluggishly, and conversely in cholecystectomy patients that the short half life is due to normal excretion from a small pool circulating more frequently than normal.

For example, when the pool circulates more frequently more bile salt passes through the liver, and as a result of the hepatic negative feedback mechanism hepatic synthesis falls and the pool shrinks. Eventually a new steady state will be established where a decreased pool circulating more frequently will return the same daily amount of bile salt to the liver as a normal pool circulating normally. With a normal return of taurocholate to the liver, synthesis returns to normal. Such a mechanism, the regulation of pool size by the frequency of enterohepatic circulation of the pool, is the only simple explanation of all the data. Moreover, this process will tend to maintain a normal amount of bile salt perfusing the intestine and biliary tree irrespective of the frequency of circulation.

Could such a mechanism help to explain the small bile salt pool found by Vlahcevic et al. $(1970,1972)$ and Bell et al. (1972) in patients with cholesterol gall stones? The evidence from this work is suggestive. The cholic acid pool plotted against its half life in patients with gall stones is shown in fig. 2. The two measurements are correlated. Neither are

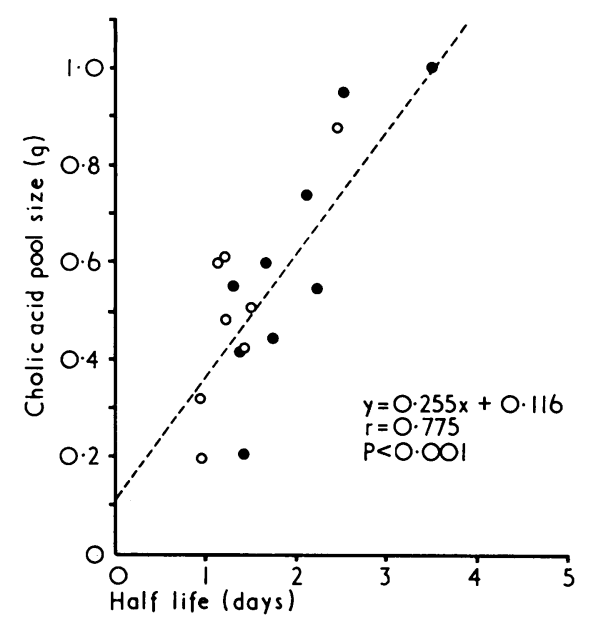

FIG. 2-Cholic acid pool size plotted against its half life in patients with gall stones. Data from Bell et al., 1972 and Vlahcevic et al., 1972. $=$ Male patients. $O=U . S$. Indian women.

correlated with daily synthesis. The simplest explanation of the reduced half life in these patients would be an increase in circulation of the pool. A defect in ileal reabsorption, to account for the data, would have to be accompanied by a reduced sensitivity of the hepatic feedback system. Indeed studies at the Mayo Clinic in gall stone patients have suggested that bile acid output is unrelated to pool size, since persons with decreased pools have increased recycling frequency (Hofmann et al., 1973). Independent evidence favouring a more frequent circulation in gall stone patients is still tenuous. The analyses by Sarles et al. (1969) of the dietary habits of gall stone patients showed that they differed from controls only by a highly significant increase in calorie intake. Brunner et al. (1972) have shown that increasing calorie intake leads to increased circulation of the bile salt pool. Therefore, excessive calories may be one of several factors leading to a small bile salt pool in gall stone patients.

The regulation of the pool size of chenodeoxycholate, the other principal bile salt, may be different from that of cholate. The limited amount of information from studies on U.S. Indians with gall stones and their controls (Bell et al., 1972; Vlahcevic et al., 1972) shows no statistical relation between chenodeoxycholate pool size and half life. Moreover, there is evidence that chenodeoxycholate synthesis is regulated by the amount of circulating deoxycholate (Low-Beer et al., 1972).

When the enterohepatic circulation is intact the liver seems to respond to changes in cycling frequency by adjusting the size of the cholate pool but maintaining synthesis at a normal level. When the circulation is interrupted the liver responds by increasing synthesis (Small et al., 1972; Hofmann, 1967). This difference should have important implications as regards the secretion of lithogenic bile-that is, bile containing relatively insufficient bile salt and phospholipid to keep biliary cholesterol in micellar solution (Admirand and Small, 1968). Since the small bile salt pool in gall stone (Vlahcevic et al., 1970, 1972; Bell et al., 1972) and cholecystectomy (Pomare and Heaton, 1973) patients appears to be circulating more frequently, daily bile salt secretion should be normal. Therefore, the small bile salt pool is unlikely to be the main cause of the lack of bile salt relative to cholesterol in lithogenic bile. Indeed the tendency for patients with cholesterol gall stones to secrete lithogenic bile disappears after cholecystectomy (Schaffer et al., 1972; Simmons et al., 1972) although the pool size does not expand (Pomare and Heaton, 1973).

On the other hand, interruption of the enterohepatic circulation can often lead to a decrease in daily bile salt secretion into the biliary tree and intestine (Hofmann, 1967; van Deest $e t$ al., 1968; Small et al., 1972) and it is probably an absolute decrease in bile salt secretion that leads to lithogenic bile (Dowling 
et al., 1972; Small et al., 1972) and the propensity to form gall stones after ileal resection (Heaton and Read, 1969).

In conclusion, the data on the enterohepatic circulation of cholate in coeliac and cholecystectomy patients and control subjects suggest that the large pools in coeliac patients and the small pools in cholecystectomy and probably also in gall stone patients are primarily due to changes in frequency of enterohepatic circulation of the pool. This hypothesis is shown diagrammatically in fig. 3.

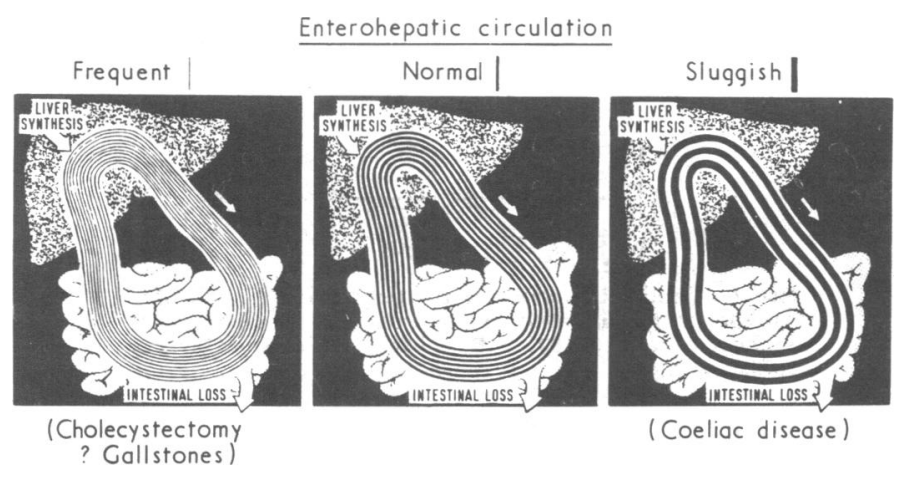

FIG. 3-Schematic representation of relation between number of times bile salt pool circulates (No. of lines) and size of pool (thickness of lines) when sait pool circulates (No. of lines) and size of pool (thickness of lines) when (total width of bands) is same in each case; so is proportion excreted and (total width of bands) is same in each case; so is proportion excreted and
therefore total daily synthesis. (Contrast with scheme in Hofmann, 1967, showing effects of broken enterohepatic circulation.)

\author{
References \\ Admirand, W. H., and Small, D. M. (1968). Fournal of Clinical Investigation, \\ 47, 1043.
}

Austad, W. I., Lack, L., and Tyor, M. P. (1967). Gastroenterology, 52, 638. Bell, C. C., et al. (1972). Surgery, Gynecology and Obstetrics, 134, 473.

Bergström, S., and Danielsson, H. (1968). In Handbook of Physiology, section 6, vol. V, p. 2391. Washington, D.C., American Physiological Society.

Boyd, G. S., and Eastwood, M. A. (1968). Biochimica Biophysica Acta, 15, 159.

Brunner, H., Hofmann, A. F., and Summerskill, W. H. J. (1972). Gastroenterology, 62, 188.

Danzinger, R. G., Hofmann, A. F., Schoenfield, L. J., and Thistle, J. L. (1972). New England fournal of Medicine, 286, 1

Di Magno, E. P., Go, V. L. W., and Summerskill, W. H. J. (1972). Gastroenterology, 63, 25.

Dowling, R. H., Bell, G. D., and White, J. (1972). Gut, 13, 415.

Grundy, S. M., Metzger, A. L., and Adler, R. D. (1972). Fournal of Clinical Investigation, 51, 3026

Heaton, K. W. (1972). Bile Salts in Health and Disease. Edinburgh, Churchill

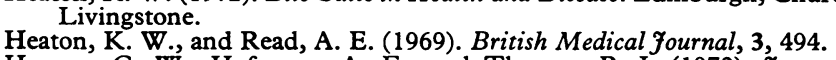

Hepner, G. W., Hofmann, A. F., and Thomas, P. J. (1972). Fournal of Clinical Investigation, 51, 1889 .

Hofmann, A. F. (1967). Gastroenterology, 52, 752.

Hofmann, A. F., Schoenfield, L. J., Kottke, B. A., and Poley, J. R. (1970). In Methods in Medical Research, vol. XII, p. 149. Chicago, Year Book Medical Publishers.

Hofmann, A. F., Northfield, T. C., and Thistle, J. L. (1973). New England fournal of Medicine, 288, 46.

Low-Beer, T. S., Heaton, K. W., Heaton, S. T., and Read, A. E. (1971). Lancet, 1, 991 .

Low-Beer, T. S., Pomare, E. W., and Morris, J. S. (1972). Nature New Biology, 238, 215.

Low-Beer, T. S., Heaton, K. W., Pomare, E. W., and Read, A. E. (1973).,

Gut, 14, 204.
Malagelada, J. R., Go, V. L. W., Gamble, W. S., and Summerskill, W. H. J. (1972). Gastroenterology, 62, 780.

Mosbach, E. H. (1972). Archives of Internal Medicine, 130, 478.

Pomare, E. W., and Heaton, K. W. (1973). In preparation.

Sarles, H., et al. (1969). American fournal of Digestive Diseases, 14, 531.

Schaffer, E. A., Braasch, J. W., and Small, D. M. (1972). New England Fournal of Medicine, 287, 1317.

Simmons, F., Ross, A. P. J., and Bouchier, I. A. D. (1972). Gastroenterology, 63, 466.

Small, D. M., Dowling, R. H., and Redinger, R. N. (1972). Archives of Internal Medicine, 130, 552.

van Deest, B. W., Fordtran, J. S., Morawski, S. G., and Wilson, J. D. (1968). Fournal of Clinical Investigation, 47, 1314.

Vlahcevic, Z. R., Bell, C. C., Buhac, I., Farrar, J. T., and Swell, L. (1970). Gastroenterology, 59, 165.

Vlahcevic, Z. R., et al. (1972). Gastroenterology, 62, 73.

\title{
Plasma Osmolality and Feeding Practices of Healthy Infants in First Three Months of Life
}

\author{
D. P. DAVIES
}

British Medical fournal, 1973, 2, 340-342

\section{Summary}

Plasma osmolality was measured in 60 healthy infants aged 1 to 3 months. The mean plasma osmolality in the 14 breast-fed infants (group $A$ ) was $284.3 \mathrm{mOsm} / 1$. Nine infants fed artificial milk formulae alone (group B) had a mean value of $293.8 \mathrm{mOsm} / 1 . ; 37$ infants already receiving solid foods in addition to artificial milk formulae (group C) had a mean value of $297 \cdot 1 \mathrm{mOsm} / 1$. The number of individual observations in the hyperosmolar range (more than $300 \mathrm{mOsm} / 1$.) in groups $\mathbf{A}, \mathbf{B}$, and $\mathbf{C}$ were 0 , 1 , and 15, accounting respectively for $0 \%, 11 \cdot 1 \%$, and $\mathbf{4 0 . 5} \%$ of the total number of observations in each group.

These results suggest that the early introduction to solid foods and the widespread use of artificial milk formulae

\footnotetext{
Department of Child Health, Welsh National School of Medicine, Cardifi CF4 4XN

D. P. DAVIES, M.R.C.P., D.C.H., Lecturer
}

at the expense of breast-feeding during the first three months of life result in an excessive dietary solute intake. This considerably stretches the ability of the immature kidney to maintain normal plasma tonicity. Minimal loss of water could precipitate a dangerous situation for babies with hyperosmolar plasma.

\section{Introduction}

Feeding practices for young infants have undergone considerable changes in recent years, with artificial dried milk formulae largely replacing breast-feeding, and solid foods being introduced at a much earlier age than was previously recommended (Taitz, 1971). It has also been suggested more recently (Taitz and Byers, 1972) that another feeding practice has insidiously developed-namely, a tendency for mothers to use excessive amounts of dried milk powder when reconstituting the feed so that milk formulae which are much too concentrated are offered to young infants. There is little doubt that artificial milk feeds and the early introduction of solid food can be held responsible for the greatly increased incidences of excessive weight gain in early infancy (Taitz, 1971), but the practice of preparing artificial milk feeds from heaped scoops instead of complying with the 